\title{
Investigation of Localized Delivery of Diclofenac Sodium from Poly(D,L-Lactic Acid-co-Glycolic Acid)/ Poly(Ethylene Glycol) Scaffolds Using an In Vitro Osteoblast Inflammation Model
}

\author{
Laura E. Sidney, PhD, ${ }^{1}$ Thomas R.J. Heathman, MEng, ${ }^{1,2}$ Emily R. Britchford, MSc, ${ }^{1,2}$ Arif Abed, MEng, \\ Cheryl V. Rahman, PhD, and Lee D.K. Buttery, PhD ${ }^{1}$
}

Nonunion fractures and large bone defects are significant targets for osteochondral tissue engineering strategies. A major hurdle in the use of these therapies is the foreign body response of the host. Herein, we report the development of a bone tissue engineering scaffold with the ability to release anti-inflammatory drugs, in the hope of evading this response. Porous, sintered scaffolds composed of poly(D,L-lactic acid-co-glycolic acid) (PLGA) and poly(ethylene glycol) (PEG) were prepared with and without the anti-inflammatory drug diclofenac sodium. Analysis of drug release over time demonstrated a profile suitable for the treatment of acute inflammation with $\sim 80 \%$ of drug released over the first 4 days and a subsequent release of around $0.2 \%$ per day. Effect of drug release was monitored using an in vitro osteoblast inflammation model, comprised of mouse primary calvarial osteoblasts stimulated with proinflammatory cytokines interleukin-1 $\beta$ (IL-1 $\beta$ ), tumor necrosis factor- $\alpha$ (TNF- $\alpha)$, and interferon- $\gamma$ (IFN- $\gamma$ ). Levels of inflammation were monitored by cell viability and cellular production of nitric oxide (NO) and prostaglandin $\mathrm{E}_{2}\left(\mathrm{PGE}_{2}\right)$. The osteoblast inflammation model revealed that proinflammatory cytokine addition to the medium reduced cell viability to $33 \%$, but the release of diclofenac sodium from scaffolds inhibited this effect with a final cell viability of $\sim 70 \%$. However, releasing diclofenac sodium at high concentrations had a toxic effect on the cells. Proinflammatory cytokine addition led to increased $\mathrm{NO}$ and $\mathrm{PGE}_{2}$ production; diclofenac-sodium-releasing scaffolds inhibited NO release by $\sim 64 \%$ and $\mathrm{PGE}_{2}$ production by $\sim 52 \%$, when the scaffold was loaded with the optimal concentration of drug. These observations demonstrate the potential use of PLGA/PEG scaffolds for localized delivery of anti-inflammatory drugs in bone tissue engineering applications.

\section{Introduction}

$\mathbf{N}$ ONUNION FRACTURES, large bone defects, and diseases such as rheumatoid arthritis are significant targets for osteochondral tissue engineering strategies. Under normal circumstances, bone has a significant capacity for regeneration and is one of the few tissues that can heal without a scar. ${ }^{1}$ Fracture healing consists of three stages: inflammation, repair, and remodeling. The initial inflammatory phase plays a critical role in healing and many of the processes that occur at this stage determine the outcome of bone repair. Within $24 \mathrm{~h}$ of bone injury, neutrophils and macrophages will have migrated into the wound site and levels of tumor necrosis factor- $\alpha$ (TNF- $\alpha)$, interleukin-1 (IL-1), interferon- $\gamma($ IFN- $\gamma$ ), and interleukin-6 (IL-6) will reach their peak. $^{2-4}$ These cytokines lead to recruitment of additional cells involved in inflammation, promotion of angiogenesis, and mesenchymal stem cell differentiation. The acute inflammatory phase usually lasts for 1 week, after which levels of inflammatory mediators return to baseline. ${ }^{4-7}$ During the subsequent remodeling phase of fracture healing, the expression levels of cytokines, such as IL-1, TNF- $\alpha$, and IL-6, rise once more, but do not reach the levels of the acute inflammatory response. ${ }^{8}$

Due to the complexity of processes involved in fracture healing, there are clinical indications where inflammation fails to resolve the problem, such as inflammatory diseases, severe body reactions, and nonunion fractures. The current

\footnotetext{
${ }^{1}$ Division of Drug Delivery and Tissue Engineering, School of Pharmacy, Centre for Biomolecular Sciences, University of Nottingham, Nottingham, United Kingdom.

${ }^{2}$ EPSRC Doctoral Training Centre in Regenerative Medicine, University of Nottingham, Nottingham, United Kingdom.
} 
"gold-standard" treatment for nonunion fractures and defects is autologous bone grafts. However, such grafts are limited due to availability and have disadvantages, such as donor site morbidity, additional surgery, and chronic pain. This has inspired the development of tissue-engineered bone substitutes. These bone substitutes are required to provide mechanical stability, support cell growth, and aid bone regeneration.

A common disadvantage of any tissue-engineered therapy is inflammation and foreign body response, upon implantation and degradation. ${ }^{9}$ Thus, the adaptation of a bone tissue engineering scaffold that provides release of antiinflammatory mediators could potentially enhance the properties of the therapy and improve success rates upon implantation. ${ }^{10,11}$

In this study, we investigate release of the anti-inflammatory drug diclofenac sodium from porous poly(D,L-lactic acidco-glycolic acid) (PLGA)/poly(ethylene glycol) (PEG) microparticle-based scaffolds. Nonsteroidal anti-inflammatory drugs (NSAIDs), such as diclofenac, have systemic treatment side effects of gastrointestinal ulceration and bleeding, hepato-renal dysfunction, and skin reactions. ${ }^{12}$ Local delivery of this drug via scaffolds offers a method of bypassing the side effects of systemic drug treatment. The properties of the PLGA/PEG scaffolds have been reported and are established as suitable for bone repair. ${ }^{13-15}$ The scaffold has demonstrated efficacy in the sustained release of growth factors, antibiotics, and chemotherapeutics. ${ }^{14,16,17}$ The potential exploitation of the scaffold as an anti-inflammatory-drugdelivery vehicle will enhance the existing osteoinductive properties of the PLGA/PEG scaffolds in bone repair. The scaffolds are manufactured from PLGA/PEG microparticles that form a paste when mixed with a carrier solution. This paste can be easily injected or pasted into the area of interest and subsequently solidifies at body temperature forming a porous scaffold.

Current validation methods for testing the properties and effectiveness of anti-inflammatory drugs released as part of tissue engineering studies are predominantly in vivo animal models. ${ }^{18-20}$ Current in vitro models are few and far between but involve the use of tissue slices. ${ }^{21-23}$ In this study, a simple in vitro calvarial osteoblast inflammation model is created using the proinflammatory cytokines IL- $1 \beta, \mathrm{TNF}-\alpha$, and IFN- $\gamma$. This model is then used to evaluate the effects of anti-inflammatory drug release from the PLGA/PEG scaffolds. Common markers of the effects of proinflammatory cytokines on osteoblasts, such as viability, nitric oxide (NO) production, and prostaglandin $\mathrm{E}_{2}\left(\mathrm{PGE}_{2}\right)$ production, are used to assess the efficacy of drug release. ${ }^{24,25}$ The in vitro model is not intended to replace animal models, but offers a simple initial step to gather information about effectiveness of drug release from scaffolds.

\section{Materials and Methods}

\section{Extraction and culture of primary calvarial osteoblasts}

Primary calvarial osteoblasts were obtained from 1- to 3day-old CD1 mouse calvaria by sequential enzymatic digestion. Calvaria were dissected and digested in a solution of $1.4 \mathrm{mg} / \mathrm{mL}$ collagenase type IA (Sigma-Aldrich, Poole, United Kingdom) and $0.5 \mathrm{mg} / \mathrm{mL}$ trypsin II S (Sigma-Aldrich). Cells released during the first two digestions $(10 \mathrm{~min})$ were discarded, and populations of cells from the next three digestions
(20 min) were plated in tissue culture flasks at a density of $6.6 \times 10^{3}$ cells $/ \mathrm{cm}^{2}$. Cells were cultured in minimum essential medium- $\alpha$ ( $\alpha$ MEM; Lonza, Verviers, Belgium), containing $10 \%$ fetal bovine serum (FBS; Sigma-Aldrich), $2 \mathrm{mM}$ L-glutamine (Sigma-Aldrich), $100 \mathrm{U} / \mathrm{mL}$ penicillin, and $100 \mu \mathrm{g} / \mathrm{mL}$ streptomycin (Sigma-Aldrich). For experimentation, cells were passaged via trypsin/EDTA, plated at a density of 10,600 cells $/ \mathrm{cm}^{2}$, and allowed to adhere overnight in well plates. Medium was subsequently supplemented with $50 \mathrm{mM} \beta$-glycerophosphate (BGP; Sigma-Aldrich) and $50 \mu \mathrm{g} / \mathrm{mL}$ ascorbate 2-phosphate (Sigma-Aldrich), to induce osteogenic differentiation.

\section{Proinflammatory cytokine treatment}

Recombinant human IL-1 $\beta$, human TNF- $\alpha$, and mouse IFN- $\gamma$ (R\&D Systems, Minneapolis, MN) were added to the culture medium at a concentration of $0.25,2.5$, and $25 \mathrm{ng} /$ $\mathrm{mL}$, respectively, unless otherwise stated.

\section{MTS viability assay}

A tetrazolium salt assay [3-(4,5-dimethylthiazol-2-yl)-5-(3carboxymethoxyphenyl)-2-(4-sulfophenyl)-2H-tetrazolium, inner salt; MTS] (CellTiter $96^{\circledR}$ AQueous One Solution Cell Proliferation Assay; Promega, Southampton, United Kingdom) was performed as per the manufacturer's protocol. Briefly, $20 \mu \mathrm{L}$ of MTS solution was added to $100 \mu \mathrm{L}$ of culture media. After incubation for $1 \mathrm{~h}$ at $37^{\circ} \mathrm{C}$, the absorbance of each well was measured at $490 \mathrm{~nm}$ using plate reader.

\section{$N O$ and $P G E_{2}$ production}

Nitrite in culture medium was measured as an estimation of NO production, using the Griess Reagent System (Promega). Nitrite concentration within culture medium samples was determined by adding $1 \%$ sulfanilamide in $5 \%$ phosphoric acid, incubating for $5 \mathrm{~min}$ before adding $0.1 \%$ $\mathrm{N}-(1$ napthyl)ethylenediaminedihydrochloride (NED) in water. Absorbance was read after 5-min room temperature incubation at $540 \mathrm{~nm}$ with wavelength correction at $690 \mathrm{~nm}$.

$\mathrm{PGE}_{2}$ concentration within culture medium was determined by enzyme immunoassay (EIA) using a commercially available kit (R\&D Systems). Briefly, a competitive-binding EIA was performed on threefold-diluted samples. Optical absorbance was read at $450 \mathrm{~nm}$ with correction at $570 \mathrm{~nm}$.

\section{Immunocytochemistry}

After treatment with diclofenac sodium and/or proinflammatory cytokines, cell monolayers were fixed with a $4 \%$ solution of paraformaldehyde (Sigma-Aldrich). Cells were permeabilized with $0.1 \%$ (v/v) Triton X-100 (Sigma-Aldrich) for $45 \mathrm{~min}$ and washed with phosphate-buffered saline (PBS). Nonspecific binding was blocked by incubating in $3 \%$ donkey serum (Sigma-Aldrich) for $30 \mathrm{~min}$. Samples were incubated with primary antibodies at $4^{\circ} \mathrm{C}$ overnight. PBS washes were performed and samples were incubated with secondary antibodies (donkey Alexa-Fluor-488 or -546; Invitrogen, Carlsbad, CA) for $1 \mathrm{~h}$ at room temperature. Nuclear counterstaining with Hoechst 33258 was performed. Primary antibodies were goat anti-osteopontin (R\&D Systems), goat anti-osteocalcin (Millipore, Hertfordshire, United Kingdom), 
rabbit anti-collagen-I (Millipore), and goat anti-cadherin-1 (R\&D Systems). Fluorescent images were captured and processed using a Leica DM-IRB inverted microscope and Volocity imaging software (Improvision, Coventry, United Kingdom).

\section{PLGA/PEG particle production}

Thermosensitive particles were manufactured from 53kDa PLGA (85:15 DLG 4CA) (Evonik Industries, Parsippany, NJ) and PEG 400 (Sigma-Aldrich) as previously described. ${ }^{13}$ Briefly, the PLGA and PEG were blended at a ratio of $93.5: 6.5(\mathrm{w} / \mathrm{v})$, at $80-90^{\circ} \mathrm{C}$ on a hotplate and allowed to cool. Polymer blend sheets were ground into particles in a bench-top mill (Krups Mill F203) and sieved to obtain a $100-200-\mu \mathrm{m}$ particle size fraction.

\section{Diclofenac-sodium-loaded PLGA/PEG scaffold manufacture}

Scaffolds were prepared in PTFE moulds producing cylindrical scaffolds of 12-mm length and 6-mm diameter. PLGA/PEG particles were mixed manually at a ratio of 1:0.6, particles to PBS carrier solution. Diclofenac sodium (Sigma-Aldrich)-loaded scaffolds were produced by mixing particles with PBS containing diclofenac sodium. The microparticle/PBS paste was packed into the moulds. Solid scaffolds were produced after sintering at $37^{\circ} \mathrm{C}$ for $3 \mathrm{~h}$.

\section{Scanning electron microscopy}

Scaffolds were cut in half to allow the center to be imaged. Cut scaffolds were mounted on aluminum stubs and were sputter-coated with gold at an argon current rate of $30 \mathrm{~mA}$ for $3 \mathrm{~min}$. The structural morphology of the scaffolds was examined using a scanning electron microscopy (JEOL JSM-6060LV) at $10 \mathrm{kV}$.

\section{Measurement of drug release from PLGA/PEG scaffolds}

After sintering, scaffolds were removed from moulds and placed into phenol red-free $\alpha \mathrm{MEM}$ (Invitrogen, Paisley, United Kingdom), with $100 \mathrm{U} / \mathrm{mL}$ penicillin and $100 \mu \mathrm{g} / \mathrm{mL}$ streptomycin, and incubated at $37^{\circ} \mathrm{C}$. Release medium was removed for drug concentration measurements, and fresh release medium was added. Drug release was measured by ultraviolet-visible (UV-Vis) spectrophotometry at $276 \mathrm{~nm}$. Concentrations of drug within the medium were determined using calibration curves.

\section{Calvarial osteoblast inflammation model}

Osteoblasts were cultured in monolayer for 14 days in osteogenic medium. UV-sterilized scaffolds were placed in transwells above the cell monolayer with medium added to cover scaffold. During diclofenac-release experiments, medium was changed to phenol-red-free $\alpha \mathrm{MEM}$, containing $10 \% \mathrm{FBS}, 100 \mathrm{U} / \mathrm{mL}$ penicillin and $100 \mu \mathrm{g} / \mathrm{mL}$ streptomycin, $2 \mathrm{mM}$ L-glutamine, $50 \mathrm{mM}$ BGP, and $50 \mu \mathrm{g} / \mathrm{mL}$ ascorbate 2-phosphate. In experimental groups stimulated with cytokines, initial concentration was $1 \mathrm{ng} / \mathrm{mL}$ IL- $1 \beta, 10 \mathrm{ng} / \mathrm{mL}$ TNF- $\alpha$, and $100 \mathrm{ng} / \mathrm{mL}$ IFN- $\gamma$. Medium was collected after
$24 \mathrm{~h}$ and replaced with medium containing $0.25 \mathrm{ng} / \mathrm{mL}$ IL$1 \beta, 2.5 \mathrm{ng} / \mathrm{mL}$ TNF- $\alpha$, and $2.5 \mathrm{ng} / \mathrm{mL}$ IFN- $\gamma$. This medium was collected after a further $24 \mathrm{~h}$ and replaced with $0.0625 \mathrm{ng} / \mathrm{mL}$ IL- $1 \beta, 0.625 \mathrm{ng} / \mathrm{mL}$ TNF- $\alpha$, and $6.25 \mathrm{ng} / \mathrm{mL}$ IFN- $\gamma$. This medium was left for a further 5 days until experiment end at day 7 .

\section{Live/Dead $^{T M}$ viability assay}

Live/Dead $^{\mathrm{TM}}$ viability/cytotoxicity assay (Invitrogen) was performed on the cell monolayers at the end of scaffoldrelease experiments (day 7). Cell monolayers were incubated with a solution of $2 \mu \mathrm{M}$ calcein AM and $4 \mu \mathrm{M}$ EthD-1 in PBS for $30 \mathrm{~min}$ at room temperature. Monolayers were imaged using an inverted fluorescent microscope. Live/dead quantification was performed using ImageJ version $1.43 \mathrm{U}$ (NIH, Bethesda, MD).

\section{Statistical analysis}

Statistical significance between groups was analyzed using PASW Statistics 18.0.3 software. Two groups were compared by unpaired Student's $t$-test and multiple groups by one-way ANOVA.

\section{Results}

Effect of diclofenac sodium and IL-1 $\beta, T N F-\alpha$, and IFN- $\gamma$ on the in vitro responses of primary osteoblasts

The effects of diclofenac sodium on proinflammatorycytokine-treated osteoblasts were assessed prior to release from scaffolds. Primary osteoblasts were cultured in osteogenic medium for 14 days before cytokine and diclofenac addition. Cell viability was monitored over the following 21 days (Fig. 1A). Adding diclofenac sodium caused a reduction in viability over the 21 days, showing slight toxicity to the cells. The addition of IL- $1 \beta$, TNF- $\alpha$, and IFN- $\gamma$ caused a significant drop in viability over the 21 -day period, to $32 \%$ $( \pm 14 \%)$ compared with the control. The addition of diclofenac with cytokines inhibited the cytokine-induced cell death, with a viability of $92 \%( \pm 11 \%)$ at day 14 and $62 \%$ $( \pm 2.5 \%)$ at day 21 .

Figure $1 \mathrm{~B}$ and $\mathrm{C}$ shows cumulative production of nitrite and $\mathrm{PGE}_{2}$, respectively, by primary osteoblasts, in the presence of diclofenac sodium and/or proinflammatory cytokines. Addition of IL-1 $\beta, \mathrm{TNF}-\alpha$, and IFN- $\gamma$ to the medium caused significantly increased nitrite and $\mathrm{PGE}_{2}$ production, compared with control osteogenic medium and $100 \mu \mathrm{M}$ diclofenac. Nitrite accumulation in groups treated with both cytokines and diclofenac was significantly lower across all timepoints than those with cytokines alone. However, nitrite levels in this group remained significantly higher than the controls. Diclofenac sodium was effective in inhibiting $\mathrm{PGE}_{2}$ production. Accumulated $\mathrm{PGE}_{2}$ concentration in the group treated with cytokines and diclofenac remained similar to controls across all timepoints. Diclofenac sodium was shown to maintain effectiveness as an NSAID in this model across a 27-day time period.

Figure 1D shows the effect of the cytokines and diclofenac on primary osteoblast differentiation, with staining for osteopontin (OPN) with osteocalcin (OCN) (Fig. 1D) 


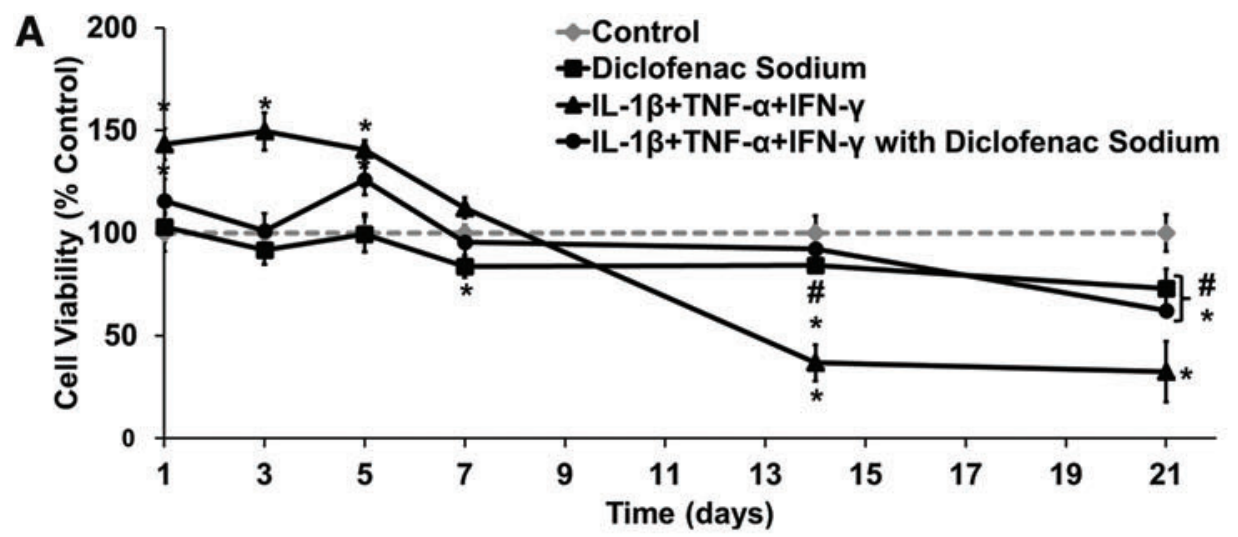

B
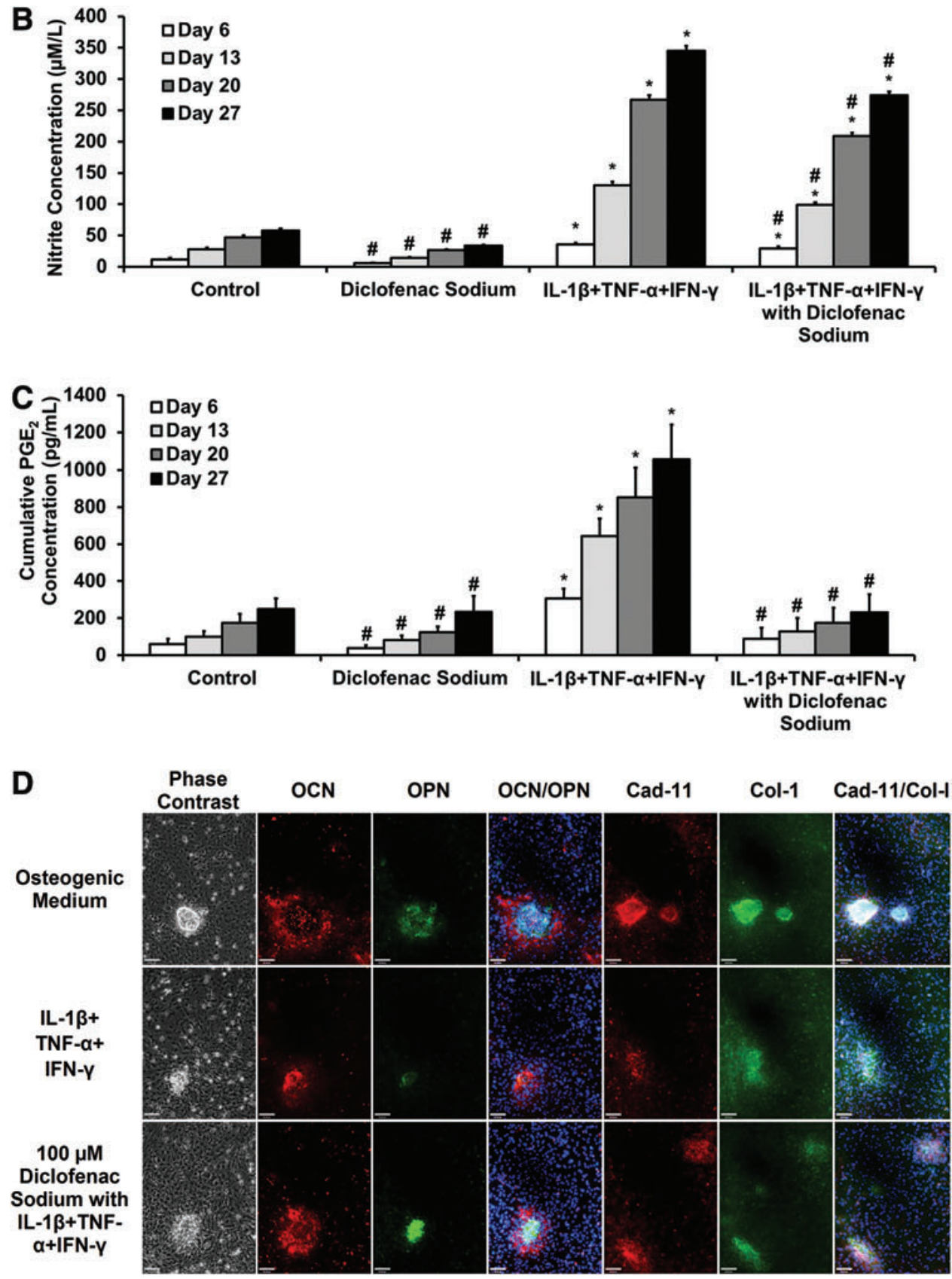

FIG. 1. Long-term effect of diclofenac sodium on response of primary calvarial osteoblasts in proinflammatory cytokine medium. Osteoblasts were cultured for 14 days in osteogenic medium before experimentation. Cytokines $(0.25 \mathrm{ng} / \mathrm{mL}$ interleukin-1 $\beta$ [IL-1 $\beta], 2.5 \mathrm{ng} / \mathrm{mL}$ tumor necrosis factor- $\alpha$ [TNF- $\alpha$ ], and $25 \mathrm{ng} / \mathrm{mL}$ interferon- $\gamma$ $[\mathrm{IFN}-\gamma]$ ) were applied throughout the 27-day period. (A) Cell viability, converted to percentage of control medium reading. Values represented as mean \pm $\mathrm{SD}, n=6$. Experiment repeated in triplicate. (B) $\mathrm{Cu}-$ mulative nitrite concentration in culture medium at timepoints. Values represented as cumulative mean \pm cumulative $\mathrm{SD}, n=6$. Experiment repeated in triplicate. $(\mathbf{C})$ Prostaglandin $\mathrm{E}_{2}\left(\mathrm{PGE}_{2}\right)$ concentration in medium at timepoints. Values represented as cumulative mean \pm cumulative SD. Experiment repeated in triplicate. For $(\mathbf{A}-\mathbf{C})$ : statistical significance versus Control, $* p \leq 0.01$. Statistical significance versus IL- $1 \beta+\mathrm{TNF}-\alpha$ + IFN- $\gamma,{ }^{\#} p \leq 0.01$. (D) Representative immunocytochemistry images showing expression of osteopontin $(\mathrm{OPN}) /$ osteocalcin (OCN) and cadherin-11 (cad-11)/collagenI (col-I) after treatment with IL-1 $\beta$, TNF- $\alpha$, and IFN- $\gamma$ and diclofenac sodium. Scale bar $=90 \mu \mathrm{m}$. OCN (red), OPN (green), OCN/OPN (Hoescht 33258 nuclear stain [blue]),

Cad-11 (red), and Col-I (green), Cad-11/Col-I (Hoescht 33258 nuclear stain [blue]). Color images available online at www .liebertpub.com/tea 
and collagen-I with cadherin-11 (Fig. 1D). Osteoblasts were cultured for 14 days in osteogenic medium before the addition of cytokines and diclofenac. Staining was subsequently performed on day 21. Compared to osteogenic medium, treatment with proinflammatory cytokines produced smaller and less-abundant nodules with dense OPN staining, little OCN, and more disperse collagen-I staining. Hoechst staining showed that there were fewer cells within nodules relative to osteogenic controls. In cells treated with proinflammatory cytokines and diclofenac, the nodules were of a similar size and cell density compared with the controls and denser staining for OCN, collagen-I, and cadherin-11 was seen than in those treated with cytokines alone.

\section{Diclofenac sodium release from PLGA/PEG scaffolds}

The PLGA/PEG scaffolds had a porous microstructure (Fig. 2A) formed by particles fusing together at $37^{\circ} \mathrm{C}$. When unconstrained, scaffolds showed a small amount of swelling after being placed in medium for drug release (Fig. 2B). In later studies, with release onto cell monolayers, scaffolds were constrained by transwells and release remained unchanged (data not shown).

The release of diclofenac sodium from the PLGA/PEG scaffolds over time was assessed by UV spectrophotometry. The cumulative mass drug release can be seen in Figure $3 \mathrm{~A}$, and converted to percentage of initial loading in Figure 3B.
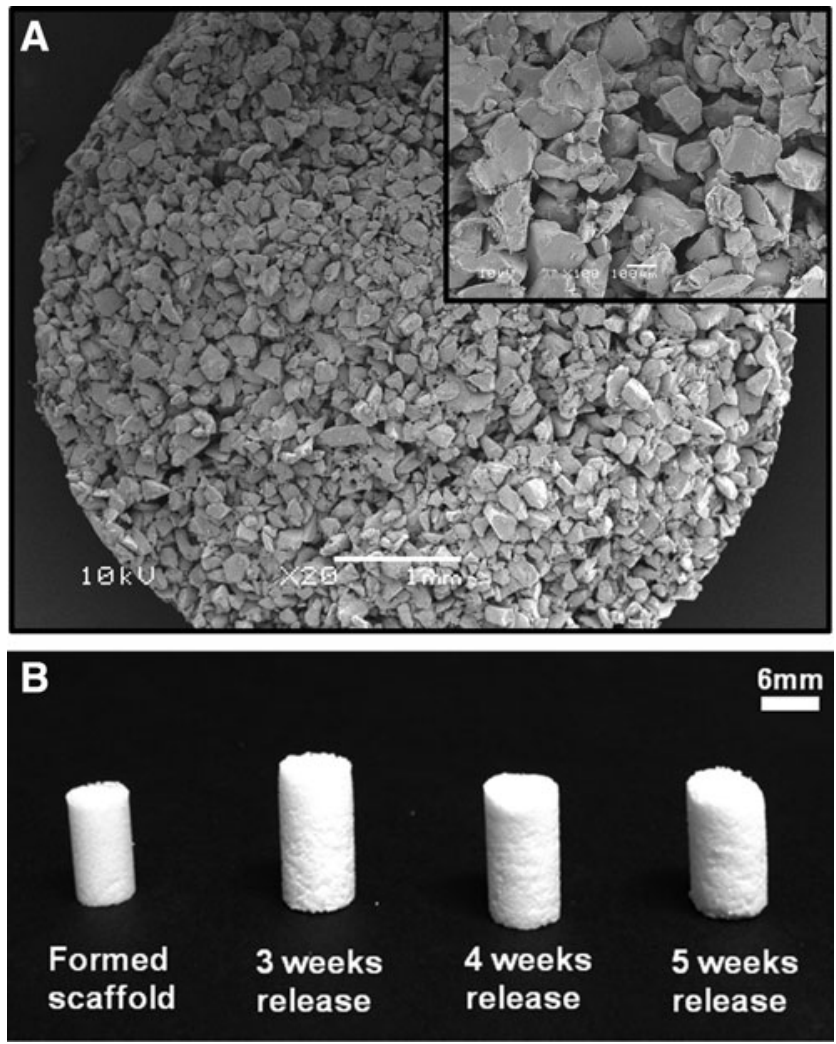

FIG. 2. Poly(D,L-lactic acid-co-glycolic acid) (PLGA)/ poly(ethylene glycol) (PEG) scaffolds. (A) Representative scanning electron microscopy images of scaffold microstructure. (B) Formed and sintered scaffolds showing swelling and degradation over 5 weeks.
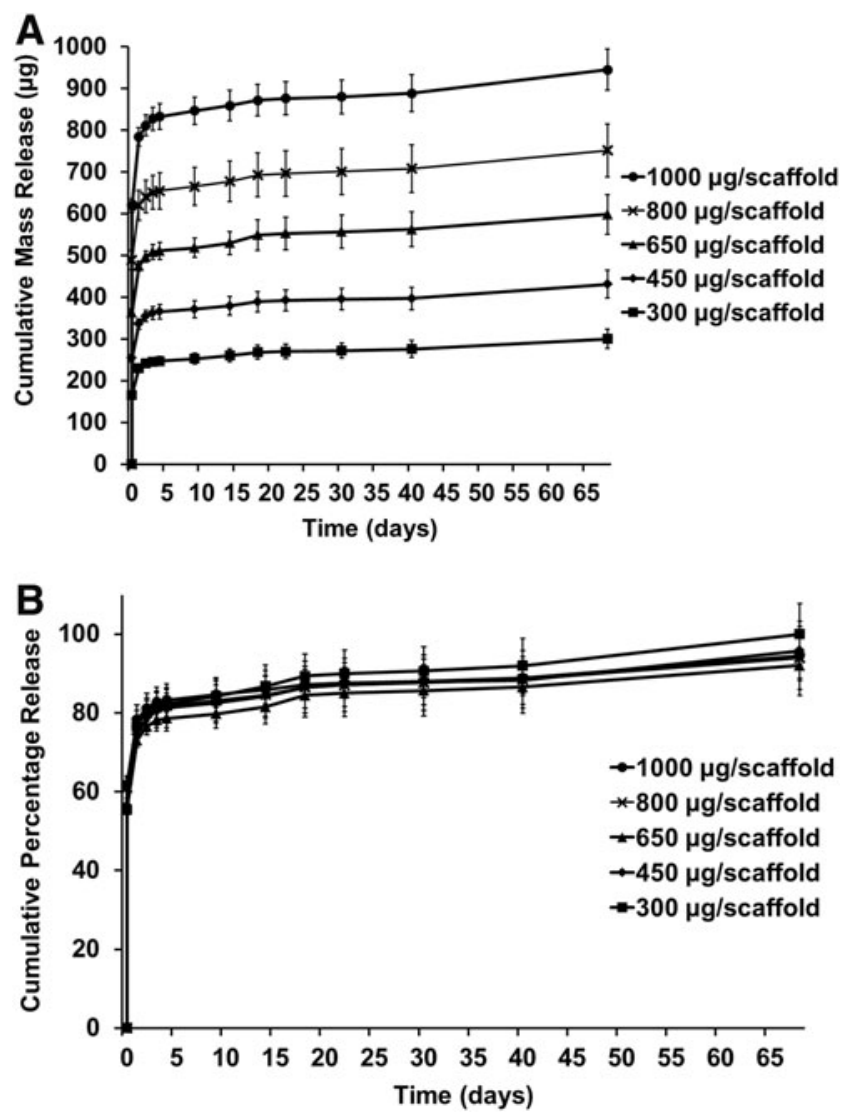

FIG. 3. Diclofenac sodium release from PLGA/PEG scaffolds. Scaffolds were loaded with varying initial concentrations of diclofenac sodium. (A) Cumulative mass release of drug over time. (B) Cumulative percentage release of drug over time. Values represented by mean of triplicate scaffold release, each measured in triplicate, $n=9$. Error represented by cumulative SD.

Scaffolds were loaded with different concentrations of diclofenac to determine effect of initial drug loading on release profile. All scaffolds showed a similar release profile regardless of original loading, with an initial burst release phase of $55-62 \%$ over the first $4 \mathrm{~h}$, followed by $\sim 20 \%$ release by day 1 , decreasing to $3 \%$ release by day 2 . After day 4 , release reached a steady state of around $0.2 \%$ per day. From day 42 , this rate increased to about $0.3 \%$ per day as the scaffolds started to degrade. By day 68 , the scaffolds had degraded and average of $96 \%( \pm 3 \%)$ of the loaded drug had been released per scaffold.

\section{Viability of primary calvarial osteoblasts after diclofenac sodium release from PLGA/PEG scaffolds}

Diclofenac-releasing scaffolds were placed in transwells above osteoblast monolayers and culture medium with and without IL-1 $\beta$, TNF- $\alpha$, and IFN- $\gamma$ added. Live/dead images were taken of the primary osteoblast monolayers after 7 days of drug release from the scaffolds (Fig. 4A) and images were quantified (Fig. 4B, C). In osteogenic medium with no scaffold and 0,300 , and $650 \mu \mathrm{g}$ of drug-loaded scaffolds, there were very few dead cells. An initial load of $1000 \mu \mathrm{g}$ 
A

nitial diclofenac sodium loading of PLGA/PEG scaffold
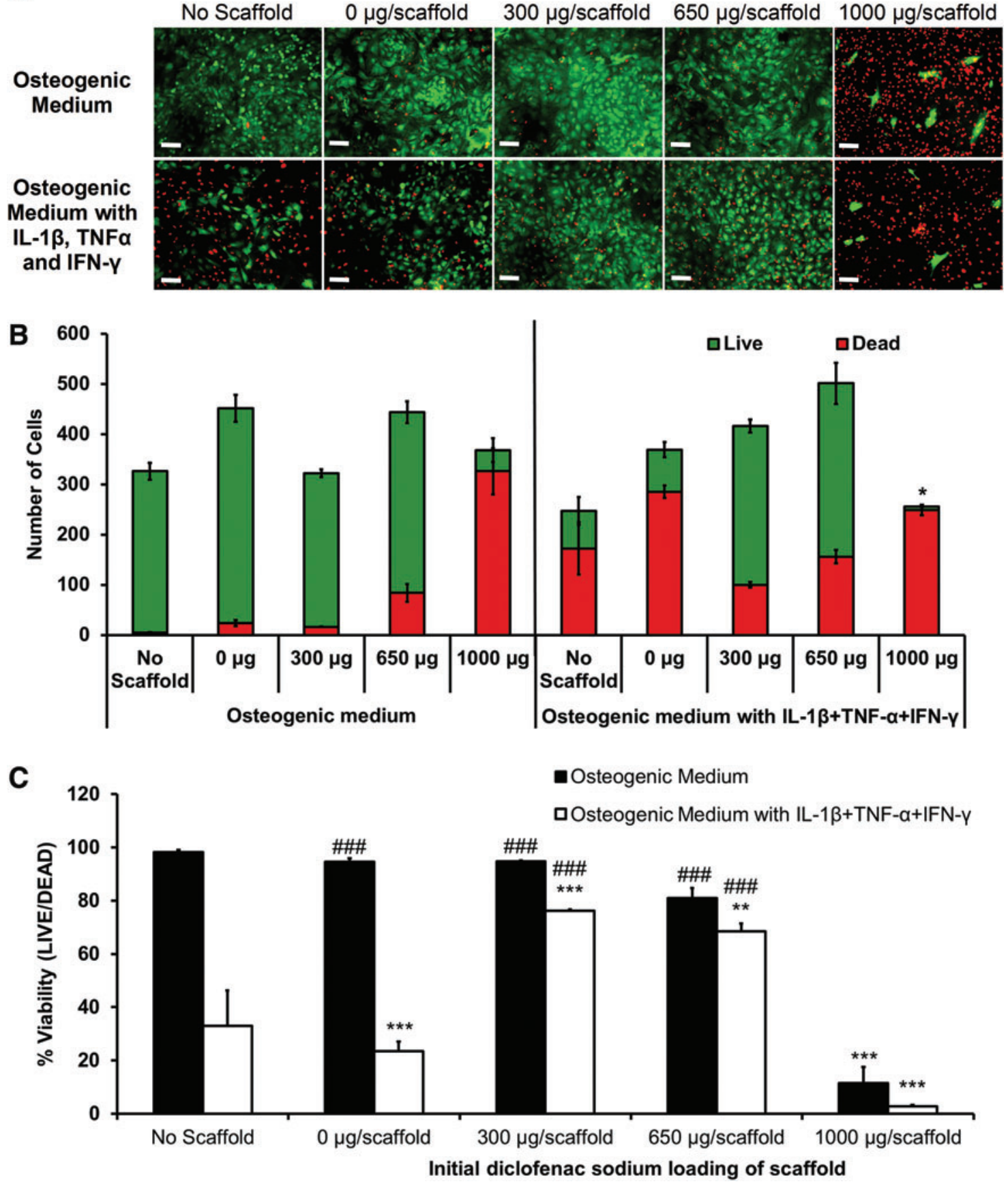

FIG. 4. Effect of diclofenac-sodium-releasing PLGA/PEG scaffolds on cell viability in the in vitro calvarial osteoblast inflammation model. Live/Dead ${ }^{\mathrm{TM}}$ viability assay of osteoblast monolayers after 7 days of culture with and without IL-1 $\beta$, TNF- $\alpha$, and IFN- $\gamma$, with PLGA/PEG scaffolds initially loaded with various masses of diclofenac sodium. (A) Representative images of osteoblast monolayers at day 7: live cells in green and dead cells in red. (B) Image quantification performed to determine average number of live and dead cells per image. Statistical significance of total cell number versus total cell number in $0 \mu \mathrm{g} / \mathrm{scaffold}$ in osteogenic medium, ${ }^{*} p \leq 0.01$. (C) Percentage of live cells in each group. Statistical significance versus $0 \mu \mathrm{g} /$ scaffold in osteogenic medium, $* * p \leq 0.001$, ***p $\leq 0.0001$. Statistical significance versus $0 \mu \mathrm{g} / \mathrm{scaffold}$ in cytokine medium, ${ }^{\# \#} p \leq 0.0001$. Experiment repeated in triplicate, each with $n=3$. Color images available online at www.liebertpub.com/tea

caused a large increase in the number of dead cells and lowered the percentage viability to below $20 \%$, indicating a toxic burst-release. In medium containing IL- $1 \beta, \mathrm{TNF}-\alpha$, and IFN- $\gamma$, with no scaffold and $0-\mu$ g scaffolds, there was a large fall in cell viability, to $33 \%$ and $23 \%$, respectively.
Release of diclofenac from the 300- and 650- $\mu \mathrm{g}$ scaffolds improved cell viability in cytokine medium to $76 \%$ and $68 \%$ correspondingly. The 1000- $\mu$ g-loaded scaffold in cytokine medium showed an enhanced negative effect with significantly less total cells and a viability of $3 \%$. 
Effect of diclofenac-sodium-releasing PLGA/PEG scaffolds on NO production in the osteoblast inflammation model

Levels of nitrite in the medium were measured after days 1 and 2 and at day 7, to estimate NO production (Fig. 5). In osteogenic control medium with and without scaffolds, there was minimal NO production. When proinflammatory cytokines were present, the control (no scaffold) and the $0-\mu \mathrm{g}$ scaffold showed significantly increased NO, at all timepoints. The 300- $\mu$ g-diclofenac-releasing scaffolds showed no significant NO production on day 1 , but day-2 and -7 levels were significantly increased. The $650-\mu \mathrm{g}$ scaffolds showed inhibition of NO production at all timepoints, although by day 7 , concentrations were also increased significantly higher than no-cytokine control. Scaffolds releasing $1000 \mu \mathrm{g}$ diclofenac showed low nitrite production across all timepoints, but low levels can be correlated with low cell viability. Cumulative nitrite production across the 7 days (Fig. 5B) shows that the $650-\mu \mathrm{g}$-loaded scaffolds significantly inhibited cytokine-induced NO production, with a reduction of $\sim 64 \%$, compared with the $0-\mu \mathrm{g}$ scaffold in cytokine medium.

\section{Effect of diclofenac-sodium-releasing PLGA/PEG scaffolds on $P G E_{2}$ production in the osteoblast inflammation model}

Concentration of $\mathrm{PGE}_{2}$ in the culture medium was measured on days 1, 2, and 7 (Fig. 6). $\mathrm{PGE}_{2}$ concentration across all groups at all timepoints can be seen in Figure 6A. When all groups are evaluated on the same graph, the "no scaffold" experimental group in cytokine medium shows a very large amount of $\mathrm{PGE}_{2}$ production, skewing the data; this can also be seen in the cumulative data (Fig. 6B). It was expected that similar levels of $\mathrm{PGE}_{2}$ would be produced by cells with $0-\mu \mathrm{g}$ scaffolds, but this was not observed when assaying the medium. This effect could be attributed to either some of the $\mathrm{PGE}_{2}$ or proinflammatory cytokines adsorbing to the scaffold and therefore not remaining soluble in the medium, causing variation in results between those with the scaffold present and those without. However, Figure 6A does show a trend of increased $\mathrm{PGE}_{2}$ in the $0-\mu \mathrm{g}$ scaffold on days 1 and 2, compared with the 300-, 650-, and 1000- $\mu$ g-diclofenac-releasing scaffolds, indicating some inhibition of cytokine-induced $\mathrm{PGE}_{2}$ by the presence of diclofenac. To get a more valuable understanding of how the scaffolds are affecting $\mathrm{PGE}_{2}$ response, cumulative results excluding the "no scaffold" controls can be found in the inset of Figure 6B. This shows that at all timepoints, the $0-\mu \mathrm{g}$ scaffold showed increased $\mathrm{PGE}_{2}$ production in proinflammatory cytokine medium compared with control osteogenic medium. Cumulative $\mathrm{PGE}_{2}$ concentration in the medium until day 7 showed that all diclofenac-sodium-loaded scaffolds showed significant inhibition of cytokine-induced $\mathrm{PGE}_{2}$ production, with a reduction of $51.9 \%$ compared with the $0-\mu \mathrm{g}$ scaffold in cytokine medium.
FIG. 5. Effect of diclofenacsodium-releasing PLGA/PEG scaffolds on nitrite production in the in vitro calvarial osteoblast inflammation model. Nitrite accumulation was measured on days 1,2, and 7, after scaffold placed in transwell. (A) Nitrite concentration at each timepoint. (B) Cumulative nitrite concentration over 7 days. Statistical significance versus $0 \mu \mathrm{g} / \mathrm{scaffold}$ in osteogenic medium, ${ }^{*} p \leq 0.01$.

Statistical significance versus $0 \mu \mathrm{g} / \mathrm{scaffold}$ in cytokine medium, ${ }^{\#} p \leq 0.01$. Values represented as mean \pm standard error of the mean (SEM); experiment repeated in triplicate each with $n=3$.
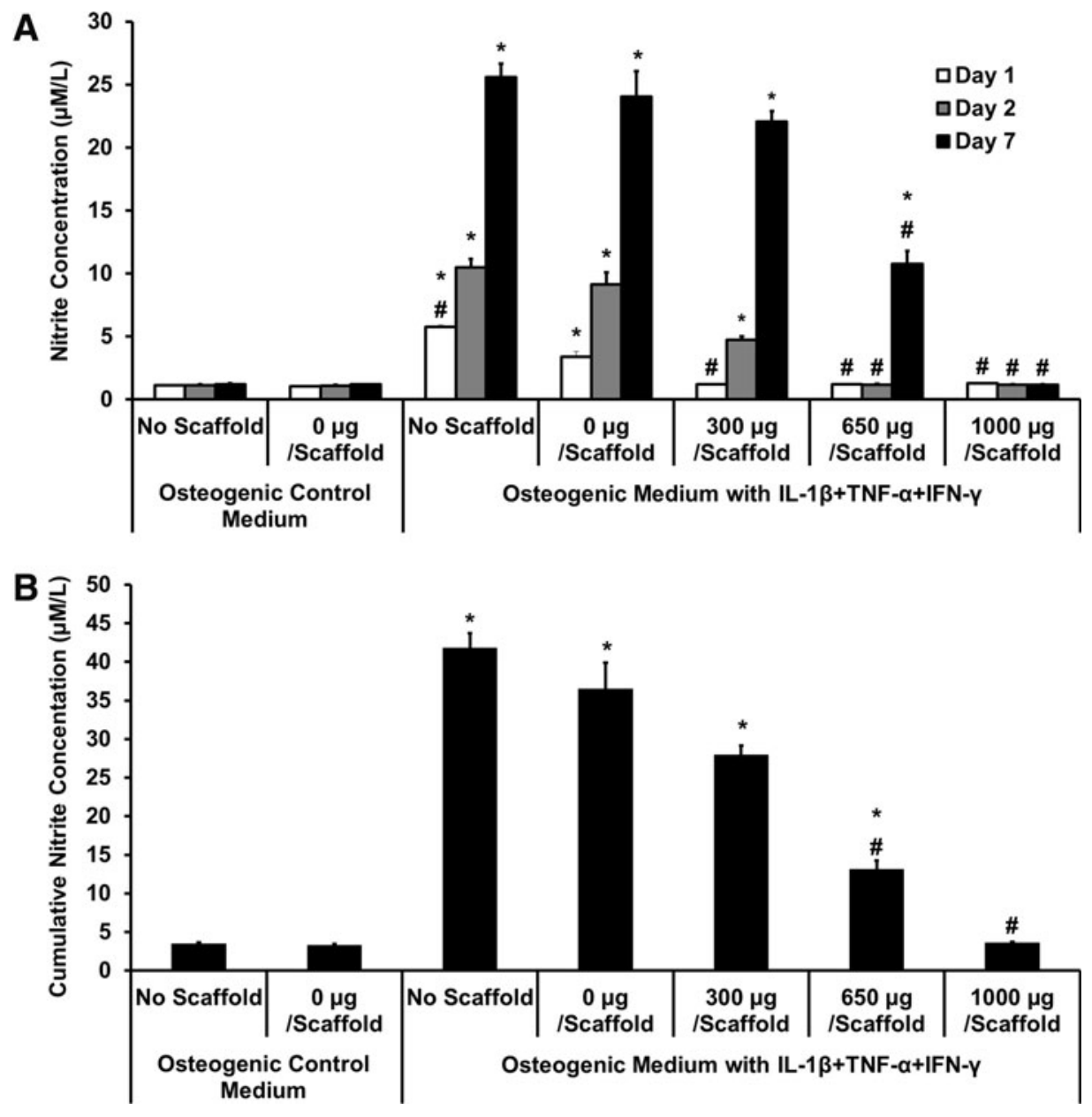

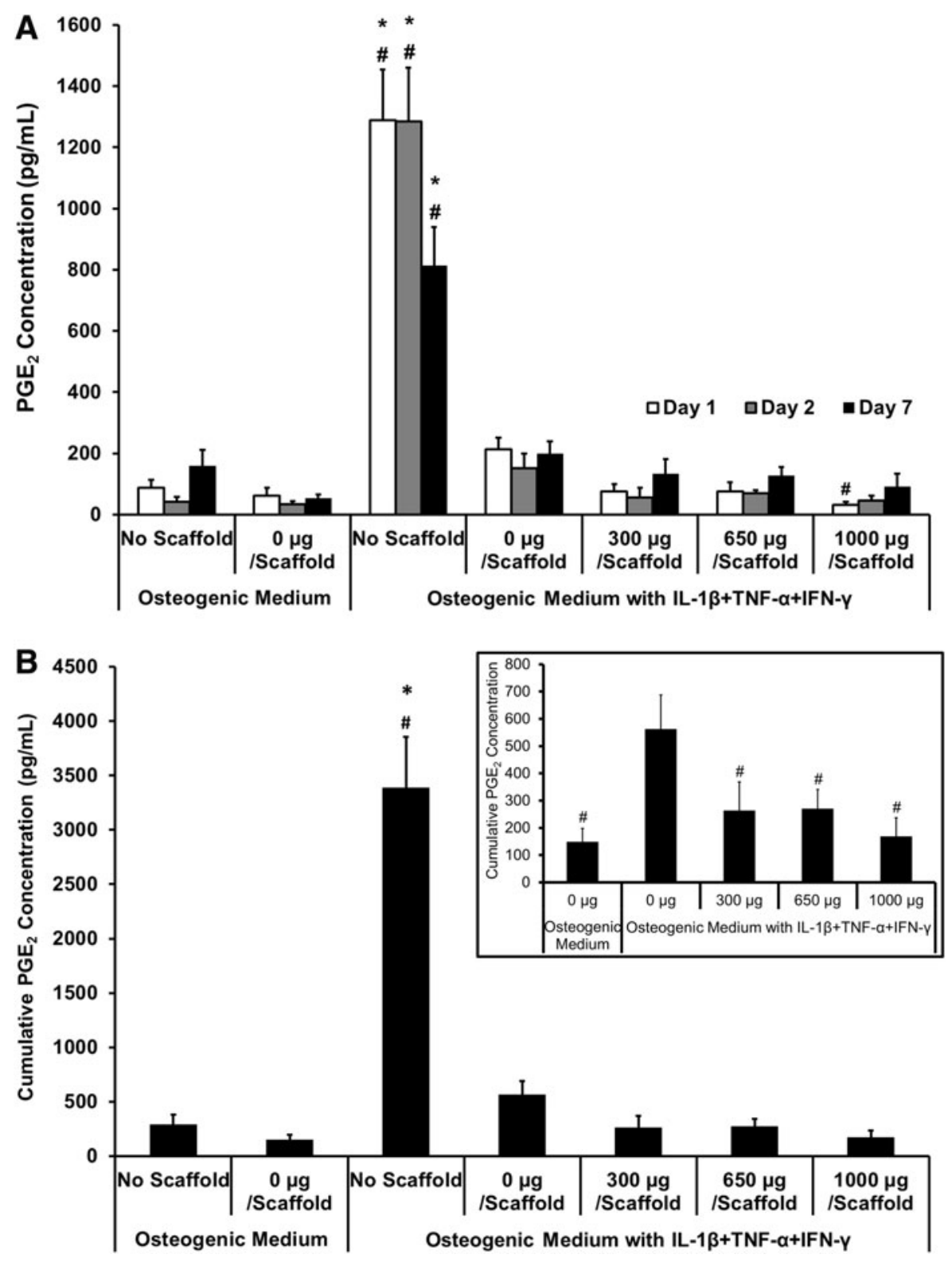

FIG. 6. Effect of diclofenacsodium-releasing PLGA/PEG scaffolds on $\mathrm{PGE}_{2}$ production in the in vitro calvarial osteoblast inflammation model. $\mathrm{PGE}_{2}$ accumulation was measured on days 1,2 , and 7 , after scaffold placed in transwell. (A) $\mathrm{PGE}_{2}$ concentration at each timepoint. (B) Cumulative $\mathrm{PGE}_{2}$ concentration over 7 days. Inset shows cumulative $\mathrm{PGE}_{2}$ concentration excluding "no scaffold" groups. Statistical significance versus $0 \mu \mathrm{g} / \mathrm{scaffold}$ in osteogenic medium, ${ }^{*} p \leq 0.01$. Statistical significance versus $0 \mu \mathrm{g} / \mathrm{scaffold}$ in cytokine medium, ${ }_{p} \leq 0.01$. Values represented as mean \pm SEM; experiment repeated in triplicate each with $n=3$.

\section{Discussion}

A major hurdle in the use of tissue-engineered therapies is the foreign body reaction of the host, associated with the implantation of the therapy. The aim of this study was the examination of PLGA/PEG scaffolds as a release vehicle for anti-inflammatory drugs, with the eventual aim of evading the foreign body response in vivo. Diclofenac sodium was chosen as the drug of choice to test this system for several reasons; NSAIDs show appealing properties as an antiinflammatory in bone treatment, good solubility in water, stability over time, successful results in both $\mathrm{PGE}_{2}$ and nitrite inhibition during in vitro tests, and, finally, available literature that describe release of diclofenac via various techniques. $^{26-28}$

$\mathrm{PGE}_{2}$ and $\mathrm{NO}$ are important inflammatory mediators produced by osteoblasts in response to proinflammatory cytokines, and can be used to monitor levels of inflammation. $^{24,25,29}$ The major mode of action of NSAIDs, such as diclofenac, is inhibition of $\mathrm{PGE}_{2}$ production through the cyclooxygenase-2 (COX-2) pathway. ${ }^{30,31} \mathrm{COX}-2$ is an inducible enzyme, generated in response to proinflammatory cytokine signaling, particularly IL- 1 and TNF- $\alpha$, leading to significantly increased production of $\mathrm{PGE}_{2}{ }^{32}$ The production of prostaglandins, such as $\mathrm{PGE}_{2}$, leads to the initial recruitment of neutrophils and subsequent recruitment of macrophages. ${ }^{33}$ The release of diclofenac from a scaffold would potentially lead to less neutrophils and macrophages at the injury site, decreasing the acute inflammatory response that leads to pain, swelling, and rejection. In some tissues this would lead to poor regeneration; however, in bone, an absence of neutrophils and macrophages may not adversely affect tissue repair. ${ }^{34,35}$

Macrophages have different phenotypes depending on the local tissue environment; the classically activated M1 phenotype is present during acute inflammation and is linked to upregulation of proinflammatory cytokines and enzymes, such as inducible nitric oxide synthase (iNOS). During tissue 
regeneration, macrophages transition to an anti-inflammatory M2 phenotype that plays a role in dampening inflammation by the production of anti-inflammatory cytokines, such as IL10 and IL-1ra. ${ }^{36,37}$ The COX-2 pathway has been linked with the transition of M1 macrophages into M2 phenotypes, and thus treatment with diclofenac may cause a delay in the transition of M1 macrophages. ${ }^{38,39}$ However in this system, effective anti-inflammatory release would only occur during the initial inflammatory stage and this transient exposure may not be enough to delay subsequent regeneration.

In this study, diclofenac sodium successfully inhibited all-cytokine-induced production of $\mathrm{PGE}_{2}$ in initial long-term cell monolayer tests. Inhibition of $\mathrm{PGE}_{2}$ production was also seen when diclofenac was released from scaffolds, although results were hampered by potential adsorption of $\mathrm{PGE}_{2}$ to the scaffold. Despite the success in this model, the complete inhibition of $\mathrm{PGE}_{2}$, and therefore COX-2, by an NSAID may not be completely desirable, as $\mathrm{COX}-2$ plays a role in bone regeneration and fracture healing. ${ }^{40-42}$ In consideration of this, the drug diclofenac may not be optimal for this purpose but in future the system could be adapted for release of anti-inflammatory drugs with alternative mechanisms of action. It is crucial to maintain the correct balance between effective anti-inflammatory function to prevent foreign body reaction, and the ability of the scaffold to regenerate bone, for this system to be successful.

The ability of NSAIDs to inhibit NO production is not as well recognized, but did occur to a certain degree in this study, in initial long-term studies and during diclofenac release from scaffolds. This result is not unexpected as NSAIDs have been shown to inhibit iNOS activity, which leads to inflammation-induced NO production. ${ }^{43,44}$ This process does not cause complete inhibition of NO production and, unlike the mode of action of anti-inflammatory glucocorticoids, it is not caused by inhibition of iNOS mRNA. ${ }^{45}$ The diclofenac sodium results in this study show partial inhibition of NO production, in agreement with this statement. Interactions have previously been shown to exist between the COX and iNOS pathways in a number of cells, including osteoblasts ${ }^{46-49}$; however, the inhibitory effects of NSAIDs on NO production have been shown to be both COX dependent and COX independent. ${ }^{44,48}$

Development and validation of the simple osteoblast inflammation model led to the development of a tissueengineered drug-release system. The injectable PLGA/PEG scaffold formulation has previously been reported and its suitability for bone tissue engineering has been demonstrated. ${ }^{13-15}$ The scaffolds were prepared from PLGA/PEG particles that form a paste when mixed with a carrier solution, in this case containing diclofenac. The paste hardens into a solid, porous scaffold when sintered at $37^{\circ} \mathrm{C}$, due to temperature-induced PEG leaching. ${ }^{13}$ During the sintering process, the diclofenac sodium in the carrier most likely becomes adsorbed or absorbed within the particles and therefore becomes physically entrapped within the pores of the resulting scaffold structure. Drug release in this system is uncontrolled, occurring via diffusion through the pores; release therefore depends upon drug properties and interaction between the drug and polymer. In this study, release consisted of a large burst within the first few hours due to drug molecules adsorbed to the surface of the scaffold immediately releasing into the medium. In some cases, this would be considered an undesirable effect, but in the case of in vivo inflammation, this burst release of anti-inflammatory drug correlates with an influx of proinflammatory cytokines upon implantation of the scaffold. After the burst, drug release slowed rapidly. From day 1 to 4 , release can be explained by diffusion of drug through water-filled pores. From day 4, release slowed substantially, but followed an almost first-order-release profile, as the remaining drug found a way through the scaffold, diffusing into the medium.

Initial loading of the drug within the scaffold had little effect on the release profile and consistency of release between batches of scaffolds correlated well. The length of time over which the majority of the diclofenac was released was about 6 days. This is in keeping with other tissueengineered anti-inflammatory release strategies that have shown 3-6 days. ${ }^{27,50,51}$ Longer, more-controlled release could be achieved by using other polymer systems, such as encapsulating the drug within microspheres fabricated by the emulsion technique. ${ }^{52,53}$ The PLGA/PEG system described herein could also be adapted by incorporating the drug into the melt-blend of the PLGA/PEG as previously demonstrated, to alter the release profile. ${ }^{16}$

Diclofenac release from scaffolds onto the osteoblast inflammation model was performed using a transwell system. This allowed the cell monolayer to be kept separate from the scaffold and did not introduce levels of complexity allowing migration of cells onto the scaffold. The transwell system allowed drug release into the cell culture medium that could freely diffuse through the pores of the membrane to the cell monolayer. The system had disadvantages; the scaffold swelled as water was imbibed and became constrained by the edges of the transwell, possibly affecting release. Nevertheless, as experiments were kept to a maximum of 7 days, this effect had little time to come into consequence. Overall, the simple system worked successfully to demonstrate that diclofenac sodium release from the scaffold remained effective as an antiinflammatory. An issue that emerged as the system developed was adsorption of $\mathrm{PGE}_{2}$ and medium proteins, such as the proinflammatory cytokines, to the PLGA/PEG scaffold. This was reflected most obviously in results for $\mathrm{PGE}_{2}$, but may also have been seen in nitrite readings, resulting in lower values when scaffolds were present. However, although there were differences between groups with and without scaffolds, when comparing scaffolds that released diclofenac to scaffolds that were not loaded with any drug, there were still significant differences, showing inhibition of the actions of the proinflammatory cytokines.

Effective drug concentration was indicated by cell viability within the osteoblast inflammation model. This was important, as anti-inflammatory drugs have been shown to induce apoptosis and arrest the cell cycle. ${ }^{54,55}$ Achieving a balance between mass of drug released to attain effective anti-inflammatory dose and the maintenance of cell viability is difficult. The highest scaffold loading of $1000 \mu \mathrm{g} / \mathrm{scaffold}$ showed almost complete cell death by day 7 of release, a property of the large initial burst. This large cell death rendered results of $\mathrm{PGE}_{2}$ and nitrite obsolete, as low values only indicated low cell numbers. There was more success with scaffolds loaded with $300-$ or $650-\mu \mathrm{g}$ diclofenac sodium. Results indicate that an initial loading between the 
two would give optimum results for cell viability and inhibition of inflammatory markers.

The in vivo inflammatory environment is vastly different to the one created in this study but as an initial validation system, prior to in vivo studies, it was successful. Overall, the PLGA/PEG scaffolds released the diclofenac in a profile that would be effective for treatment of acute inflammation and the in vitro inflammation model demonstrated that diclofenac sodium was effective after release.

\section{Acknowledgments}

The authors would like to acknowledge the staff of the Biomedical Services Unit, University of Nottingham, for provision and care of animals and Prof. Kevin Shakesheff for provision of the PLGA/PEG formulation. Funding for this study was provided by the EPSRC Doctoral Training Centre for Regenerative Medicine.

\section{Disclosure Statement}

No competing financial interests exist.

\section{References}

1. McKibbin, B. The biology of fracture healing in long bones. J Bone Joint Surg Br 60-B, 150, 1978.

2. Schaffer, M., and Barbul, A. Lymphocyte function in wound healing and following injury. Br J Surg 85, 444, 1998.

3. Gerstenfeld, L.C., Cullinane, D.M., Barnes, G.L., Graves, D.T., and Einhorn, T.A. Fracture healing as a post-natal developmental process: molecular, spatial, and temporal aspects of its regulation. J Cell Biochem 88, 873, 2003.

4. Rundle, C.H., Wang, H., Yu, H., Chadwick, R.B., Davis, E.I., Wergedal, J.E., Lau, K.H., Mohan, S., Ryaby, J.T., and Baylink, D.J. Microarray analysis of gene expression during the inflammation and endochondral bone formation stages of rat femur fracture repair. Bone 38, 521, 2006.

5. Kon, T., Cho, T.J., Aizawa, T., Yamazaki, M., Nooh, N., Graves, D., Gerstenfeld, L.C., and Einhorn, T.A. Expression of osteoprotegerin, receptor activator of NF-kappaB ligand (osteoprotegerin ligand) and related proinflammatory cytokines during fracture healing. J Bone Miner Res 16, 1004, 2001.

6. Cho, T.J., Gerstenfeld, L.C., and Einhorn, T.A. Differential temporal expression of members of the transforming growth factor beta superfamily during murine fracture healing. J Bone Miner Res 17, 513, 2002.

7. Barnes, G.L., Kostenuik, P.J., Gerstenfeld, L.C., and Einhorn, T.A. Growth factor regulation of fracture repair. J Bone Miner Res 14, 1805, 1999.

8. Mountziaris, P.M., and Mikos, A.G. Modulation of the inflammatory response for enhanced bone tissue regeneration. Tissue Eng Part B Rev 14, 179, 2008.

9. Bostman, O., and Pihlajamaki, H. Clinical biocompatibility of biodegradable orthopaedic implants for internal fixation: a review. Biomaterials 21, 2615, 2000.

10. Mourino, V., and Boccaccini, A.R. Bone tissue engineering therapeutics: controlled drug delivery in three-dimensional scaffolds. J R Soc Interface 7, 209, 2010.

11. Corry, D., and Moran, J. Assessment of acrylic bone cement as a local delivery vehicle for the application of non-steroidal anti-inflammatory drugs. Biomaterials 19, 1395, 1998.

12. Rainsford, K.D. Profile and mechanisms of gastrointestinal and other side effects of nonsteroidal anti-inflammatory drugs (NSAIDs). Am J Med 107, 27S, 1999.

13. Dhillon, A., Schneider, P., Kuhn, G., Reinwald, Y., White, L., Levchuk, A., Rose, F., Müller, R., Shakesheff, K., and Rahman, C. Analysis of sintered polymer scaffolds using concomitant synchrotron computed tomography and in situ mechanical testing. J Mater Sci Mater Med 22, 2599, 2011.

14. Rahman, C.V., Ben-David, D., Dhillon, A., Kuhn, G., Gould, T.W., Muller, R., Rose, F.R., Shakesheff, K.M., and Livne, E. Controlled release of BMP-2 from a sintered polymer scaffold enhances bone repair in a mouse calvarial defect model. J Tissue Eng Regen Med 8, 59, 2012.

15. Rahman, C.V., Kuhn, G., White, L.J., Kirby, G.T., Varghese, O.P., McLaren, J.S., Cox, H.C., Rose, F.R., Muller, R., Hilborn, J., and Shakesheff, K.M. PLGA/PEGhydrogel composite scaffolds with controllable mechanical properties. J Biomed Mater Res B Appl Biomater 101, 648, 2013.

16. Gould, T.W., Birchall, J.P., Mallick, A.S., Alliston, T., Lustig, L.R., Shakesheff, K.M., and Rahman, C.V. Development of a porous poly(DL-lactic acid-co-glycolic acid)-based scaffold for mastoid air-cell regeneration. Laryngoscope 123, 3156, 2013.

17. Rahman, C.V., Smith, S.J., Morgan, P.S., Langmack, K.A., Clarke, P.A., Ritchie, A.A., Macarthur, D.C., Rose, F.R., Shakesheff, K.M., Grundy, R.G., and Ruman, R. Adjuvant chemotherapy for brain tumors delivered via a novel intracavity moldable polymer matrix. PLoS One 8, e77435, 2013.

18. Hickey, T., Kreutzer, D., Burgess, D.J., and Moussy, F. In vivo evaluation of a dexamethasone/PLGA microsphere system designed to suppress the inflammatory tissue response to implantable medical devices. J Biomed Mater Res 61, 180, 2002.

19. Khaled, K., Sarhan, H.A., Ibrahim, M.A., Ali, A.H., and Naguib, Y.W. Prednisolone-loaded PLGA microspheres. In vitro characterization and in vivo application in adjuvantinduced arthritis in mice. AAPS PharmSciTech 11, 859, 2010.

20. Willoughby, D., and Winyard, P.G. Inflammation protocols. In: Walker, J., ed. Methods in Molecular Biology. Totowa, NJ: Humana Press, 2003.

21. Huuskonen, J., Suuronen, T., Miettinen, R., van Groen, T., and Salminen, A. A refined in vitro model to study inflammatory responses in organotypic membrane culture of postnatal rat hippocampal slices. J Neuroinflammation 2, 25, 2005.

22. Olinga, P., Merema, M.T., de Jager, M.H., Derks, F., Melgert, B.N., Moshage, H., Slooff, M.J., Meijer, D.K., Poelstra, K., and Groothuis, G.M. Rat liver slices as a tool to study LPS-induced inflammatory response in the liver. J Hepatol 35, 187, 2001.

23. Smith, E.L., Locke, M., Waddington, R.J., and Sloan, A.J. An ex vivo rodent mandible culture model for bone repair. Tissue Eng Part C Methods 16, 1287, 2010.

24. Hughes, F.J., Buttery, L.D., Hukkanen, M.V., O’Donnell, A., Maclouf, J., and Polak, J.M. Cytokine-induced prostaglandin E2 synthesis and cyclooxygenase-2 activity are regulated both by a nitric oxide-dependent and -independent 
mechanism in rat osteoblasts in vitro. $\mathrm{J}$ Biol Chem 274, 1776, 1999.

25. Akatsu, T., Takahashi, N., Udagawa, N., Imamura, K., Yamaguchi, A., Sato, K., Nagata, N., and Suda, T. Role of prostaglandins in interleukin-1-induced bone resorption in mice in vitro. J Bone Miner Res 6, 183, 1991.

26. Nikkola, L., Seppala, J., Harlin, A., Ndreu, A., and Ashammakhi, N. Electrospun multifunctional diclofenac sodium releasing nanoscaffold. J Nanosci Nanotechnol 6, 3290, 2006.

27. Tunçay, M., Caliş, S., Kaş, H.S., Ercan, M.T., Peksoy, I., and Hincal, A.A. Diclofenac sodium incorporated PLGA (50:50) microspheres: formulation considerations and in vitro/in vivo evaluation. Int $\mathrm{J}$ Pharm 195, 179, 2000.

28. Attama, A.A., Reichl, S., and Muller-Goymann, C.C. Diclofenac sodium delivery to the eye: in vitro evaluation of novel solid lipid nanoparticle formulation using human cornea construct. Int J Pharm 355, 307, 2008.

29. Sidney, L.E., Kirkham, G.R., and Buttery, L.D. Comparison of osteogenic differentiation of embryonic stem cells and primary osteoblasts revealed by responses to IL-1beta, TNF-alpha, and IFN-gamma. Stem Cells Dev 23, 605, 2014.

30. Vane, J.R., and Botting, R.M. Mechanism of action of nonsteroidal anti-inflammatory drugs. Am J Med 104, 2S, 1998.

31. Mitchell, J.A., Akarasereenont, P., Thiemermann, C., Flower, R.J., and Vane, J.R. Selectivity of nonsteroidal antiinflammatory drugs as inhibitors of constitutive and inducible cyclooxygenase. Proc Natl Acad Sci U S A 90, 11693, 1993.

32. Willoughby, D., and Tomlinson, A. Inducible enzymes in the inflammatory response. In: Parnham, M., ed. Progress in Inflammation Research. 1st ed. Basel: Birkhauser Verlag, 1999, pp. 211.

33. Kolar, P., Schmidt-Bleek, K., Schell, H., Gaber, T., Toben, D., Schmidmaier, G., Perka, C., Buttgereit, F., and Duda, G.N. The early fracture hematoma and its potential role in fracture healing. Tissue Eng Part B Rev 16, 427, 2010.

34. Martin, P., Souza, D.D., Martin, J., Grose, R., Cooper, L., Maki, R., McKercher, S.R., Fields, I., Wca, L., and Jolla, L. Wound healing in the PU.1 null mouse-tissue repair is not dependent on inflammatory cells. Curr Biol 13, 1122, 2003.

35. Toben, D., Schroeder, I., El Khassawna, T., Mehta, M., Hoffmann, J.E., Frisch, J.T., Schell, H., Lienau, J., Serra, A., Radbruch, A., and Duda, G.N. Fracture healing is accelerated in the absence of the adaptive immune system. $\mathrm{J}$ Bone Miner Res 26, 113, 2011.

36. Martinez, F.O., Sica, A., Mantovani, A., and Locati, M. Macrophage activation and polarization. Front Biosci 13, 453, 2008.

37. Duffield, J.S. The inflammatory macrophage: a story of Jekyll and Hyde. Clin Sci (Lond) 104, 27, 2003.

38. Marsolais, D., Cote, C.H., and Frenette, J. Nonsteroidal anti-inflammatory drug reduces neutrophil and macrophage accumulation but does not improve tendon regeneration. Lab Invest 83, 991, 2003.

39. Na, Y.R., Yoon, Y.N., Son, D.I., and Seok, S.H. Cyclooxygenase-2 inhibition blocks M2 macrophage differentiation and suppresses metastasis in murine breast cancer model. PLoS One 8, e63451, 2013.
40. Simon, A.M., Manigrasso, M.B., and O'Connor, J.P. Cyclo-oxygenase 2 function is essential for bone fracture healing. J Bone Miner Res 17, 963, 2002.

41. Zhang, X., Schwarz, E.M., Young, D.A., Puzas, J.E., Rosier, R.N., and O'Keefe, R.J. Cyclooxygenase-2 regulates mesenchymal cell differentiation into the osteoblast lineage and is critically involved in bone repair. J Clin Invest 109, 1405, 2002.

42. Krischak, G.D., Augat, P., Blakytny, R., Claes, L., Kinzl, L., and Beck, A. The non-steroidal anti-inflammatory drug diclofenac reduces appearance of osteoblasts in bone defect healing in rats. Arch Orthop Trauma Surg 127, 453, 2007.

43. Aeberhard, E.E., Henderson, S.A., Arabolos, N.S., Griscavage, J.M., Castro, F.E., Barrett, C.T., and Ignarro, L.J. Nonsteroidal anti-inflammatory drugs inhibit expression of the inducible nitric oxide synthase gene. Biochem Biophys Res Commun 208, 1053, 1995.

44. Amin, A.R., Vyas, P., Attur, M., Leszczynska-Piziak, J., Patel, I.R., Weissmann, G., and Abramson, S.B. The mode of action of aspirin-like drugs: effect on inducible nitric oxide synthase. Proc Natl Acad Sci U S A 92, 7926, 1995.

45. Kepka-Lenhart, D., Chen, L.C., and Morris, S.M., Jr. Novel actions of aspirin and sodium salicylate: discordant effects on nitric oxide synthesis and induction of nitric oxide synthase mRNA in a murine macrophage cell line. J Leukoc Biol 59, 840, 1996.

46. Salvemini, D., Manning, P.T., Zweifel, B.S., Seibert, K., Connor, J., Currie, M.G., Needleman, P., and Masferrer, J.L. Dual inhibition of nitric oxide and prostaglandin production contributes to the antiinflammatory properties of nitric oxide synthase inhibitors. J Clin Invest 96, 301, 1995.

47. Kanematsu, M., Ikeda, K., and Yamada, Y. Interaction between nitric oxide synthase and cyclooxygenase pathways in osteoblastic MC3T3-E1 cells. J Bone Miner Res 12, 1789, 1997.

48. Tetsuka, T., Daphna-Iken, D., Srivastava, S.K., Baier, L.D., DuMaine, J., and Morrison, A.R. Cross-talk between cyclooxygenase and nitric oxide pathways: prostaglandin E2 negatively modulates induction of nitric oxide synthase by interleukin 1. Proc Natl Acad Sci U S A 91, 12168, 1994.

49. Salvemini, D., Settle, S.L., Masferrer, J.L., Seibert, K., Currie, M.G., and Needleman, P. Regulation of prostaglandin production by nitric oxide; an in vivo analysis. Br $\mathrm{J}$ Pharmacol 114, 1171, 1995.

50. Cantón, I., McKean, R., Charnley, M., Blackwood, K.A., Fiorica, C., Ryan, A.J., and MacNeil, S. Development of an Ibuprofen-releasing biodegradable PLA/PGA electrospun scaffold for tissue regeneration. Biotechnol Bioeng 105, 396, 2010.

51. Della Porta, G., Falco, N., and Reverchon, E. NSAID drugs release from injectable microspheres produced by supercritical fluid emulsion extraction. J Pharm Sci 99, 1484, 2010.

52. Kang, Y., Wu, J., Yin, G., Huang, Z., Yao, Y., Liao, X., Chen, A., Pu, X., and Liao, L. Preparation, characterization and in vitro cytotoxicity of indomethacin-loaded PLLA/ PLGA microparticles using supercritical $\mathrm{CO} 2$ technique. Eur J Pharm Biopharm 70, 85, 2008.

53. Ju, Y.M., Yu, B.Z., West, L., Moussy, Y., and Moussy, F. A dexamethasone-loaded PLGA micirospheres/collagen 
scaffold composite for implantable glucose sensors. J Biomed Mater Res 93A, 200, 2010.

54. Chang, J.K., Li, C.J., Liao, H.J., Wang, C.K., Wang, G.J., and Ho, M.L. Anti-inflammatory drugs suppress proliferation and induce apoptosis through altering expressions of cell cycle regulators and pro-apoptotic factors in cultured human osteoblasts. Toxicology 258, 148, 2009.

55. Chang, J.K., Li, C.J., Wu, S.C., Yeh, C.H., Chen, C.H., Fu, Y.C., Wang, G.J., and Ho, M.L. Effects of anti-inflammatory drugs on proliferation, cytotoxicity and osteogenesis in bone marrow mesenchymal stem cells. Biochem Pharmacol 74, 1371, 2007.
Address correspondence to:

Lee D.K. Buttery, PhD

Division of Drug Delivery and Tissue Engineering

School of Pharmacy

Centre for Biomolecular Sciences

University of Nottingham

Nottingham NG7 2RD

United Kingdom

E-mail: lee.buttery@nottingham.ac.uk

Received: February 7, 2014

Accepted: August 1, 2014

Online Publication Date: October 3, 2014 